\title{
Evaluation of the Depth of the Curve of Spee, Overjet, and Overbite in Class I, Class II, and Class III Malocclusion among Patients at University of North Sumatera Dental Hospital
}

\author{
Nazruddin ${ }^{*}$, Tan Yan $\mathbf{Y u}^{2}$ \\ ${ }^{1}$ Department of Orthodontics, Faculty of Dentistry, University of Sumatera Utara, Kampus USU, \\ Medan, 20155, Indonesia \\ ${ }^{2}$ Faculty of Dentistry, University of Sumatera Utara, Kampus USU, Medan, 20155, Indonesia \\ *Email: mercurialvapor1995@hotmail.com
}

\begin{abstract}
The curve of Spee is an important characteristic in the mandibular arch. An optimal occlusion must have a curve of Spee ranging from flat to mild. Therefore, an understanding of the curve of Spee is essential for both diagnosis and treatment planning in orthodontics. The aim of this study was to examine the difference in both the form and depth of the curve of Spee among class I, II, and III malocclusions and investigate the relationship between the depth of the curve of Spee with both overjet and overbite among patients at the University of North Sumatera Dental Hospital. A total of 100 dental study models with ages older than 15 years were enrolled and divided into 5 malocclusion groups: class $I(n=40)$, class II division $1(\mathrm{n}=32)$, class II division $2(\mathrm{n}=10)$, class II subdivision $(\mathrm{n}=7)$, and class III $(\mathrm{n}$ $=11$ ). The depth of the curve of Spee, overjet, and overbite was measured on dental study models with a digital caliper. The depth of curve of Spee was taken as the mean measurement from both sides of the arch on dental study models. The correlation coefficient between the depth of the curve of Spee and other variables were also calculated. The results showed that a maximum mean depth of the curve of Spee of $4.65 \pm 1.41 \mathrm{~mm}$ in the class II division 2 group and a minimum depth of $2.34 \pm 0.96 \mathrm{~mm}$ in the class III group. A statistically significant correlation was also found between the depth of the curve of Spee with both overbite and overjet. In conclusion, the curve of Spee was found to be deepest in class II division 2 followed by class II division 1, class II subdivision, class I, and class III malocclusion.
\end{abstract}

Keywords: curve of Spee, overjet, overbite, malocclusion

\section{Introduction}

F. Graf von Spee, who used skulls with abraded teeth to define a line of occlusion, first described the curve of Spee in 1890. This line lies on a cylinder that is tangent to the anterior border of the condyle, the occlusal surface of the second molar and incisal edges of the mandibular incisors. Spee located the center of this cylinder in the midorbital plane so that it had a radius of 6.5 to $7.0 \mathrm{~cm}$. However, clinically, the distal marginal ridges of the posterior teeth in the arch and the incisal edges of the central incisors determine the curve of Spee. The functional significance of the curvature has not been completely understood. However, it has been suggested that 
the curve of Spee has a biomechanical function during food processing by increasing the crush-shear ratio between the posterior teeth and the efficiency of the occlusal forces during mastication [1].

The curve of Spee represents the arrangement of the planner mean of the curvature of occlusal surfaces of the mandibular teeth according to their positions in the arch. Hence, familiarity with the standard value of occlusal curvature aids in examination, diagnosis, and treatment of occlusal disharmony. One of the key clinical steps in the rehabilitation of multiple long span posterior restorations is the re-establishment of the occlusal plane. The restoration of compensating curves forms the basis for ideal teeth arrangement [2]. Andrews proposed that flattening the occlusal plane should be the treatment goal in orthodontics. The value of the curve of Spee depth as the sixth key to normal occlusion should be considered and quantified in space management procedures to prevent incisor flaring and consequently assuring aesthetics and the stability of both the treatment results and function $[3,4]$.

Research conducted by Ahmed et al. showed that the depth of the curve of Spee was deepest in class II division 2 malocclusion and was flat in class III malocclusion suggesting that the curve of Spee in the mandibular arch is influenced by the anteroposterior position of the mandible [3]. In humans, an increased curve of Spee is often seen in brachycephalic facial patterns and associated with short mandibular bodies [4]. On the other hand, Farella et al. found that the curve of Spee is more marked in short face subjects and less marked in long-face subjects. Similarly, Ahmed et al. found that the curve of Spee is deepest in class II division 2 malocclusions that have a deep overbite and short face heights (low angle) than in the normal and flat Spee groups and it was flat in class III malocclusion that has both high and low angle variants [3].

From the results of research conducted by Nayar et al., it is clear that the curve is deeper in class II cases while it is flatter in class III cases. This study correlates with Orthlieb's finding that the radius of the curve of Spee is less in class II cases while it is more in class III occlusion [5]. Leveling of the curve of Spee represents a routine procedure in orthodontic practice (Fig. 1). The deviation of the occlusal plane from a flat plane has practical consequences when considering the arch circumference requirements necessary to flatten the curve. Indisputably, a curved arch has a greater circumference than a flat arch [6].

Later on, the curve of Spee and leveling of this has been related to incisor overbite and lower arch circumference. A deep curve of Spee is usually associated with an increased overbite. Orthodontic correction of the overbite often involves leveling the curve of Spee by an anterior intrusion, posterior extrusion, or a combination of both [5]. Although leveling the curve of Spee is an everyday occurrence in orthodontic practice, little research has been dedicated to examining relationships between the depth of the curve of Spee and types of malocclusion. The aim of this study was to examine the difference in the depth of the curve of Spee within malocclusion class I, II, and III and the relationship with overjet and overbite among patients in the University of North Sumatera Dental Hospital. 

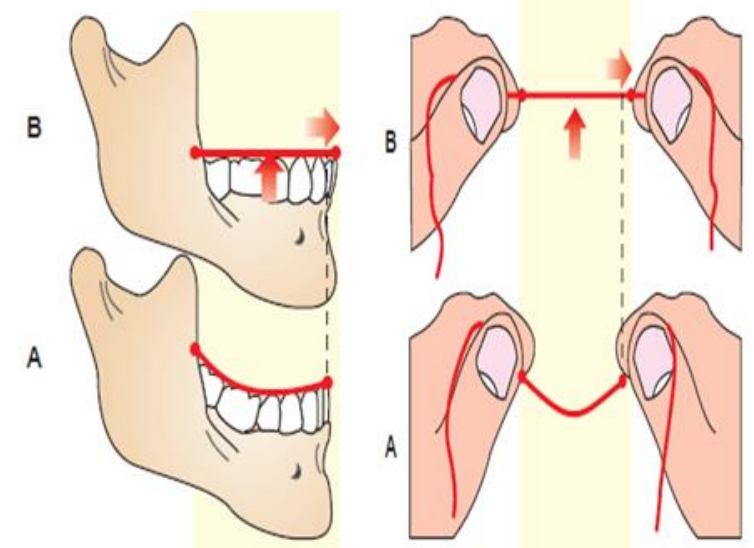

Fig. 1 Leveling of the curve of Spee[7]

\section{Materials and Methods}

This analytical study was performed by using dental study models of 100 subjects aged older than 15 years with complete permanent dentition except for the third molar and no previous orthodontic treatments. These dental study models were taken from the Department of Orthodontics of University of North Sumatera and were further divided into 5 malocclusion groups which are class I $(n=40)$, class II division $1(\mathrm{n}=32)$, class II division $2(\mathrm{n}=10)$, class II subdivision $(\mathrm{n}=7)$, and class III $(\mathrm{n}=11)$. The depth of the curve of Spee was measured as the perpendicular distance between the deepest cusp tip and a flat plane that was laid on top of the mandibular dental study models, touching the incisal edges of the central incisors and the distal cusp tips of the most posterior teeth in the lower arch with a digital caliper using the Baldridge Method (Fig. 2). The measurement was made on the right and left side of the dental arch, and the mean value of these two measurements was used as the depth of the curve of Spee. The overjet was measured as the distance along a horizontal plane between the incisal edge of the labial surface of the mandibular central incisor and the incisal edge of the labial surface of the most labially positioned maxillary central incisors. The overbite was measured as the vertical distance between the incisal edge of the maxillary central incisor and the incisal edge of the mandibular central incisor. 


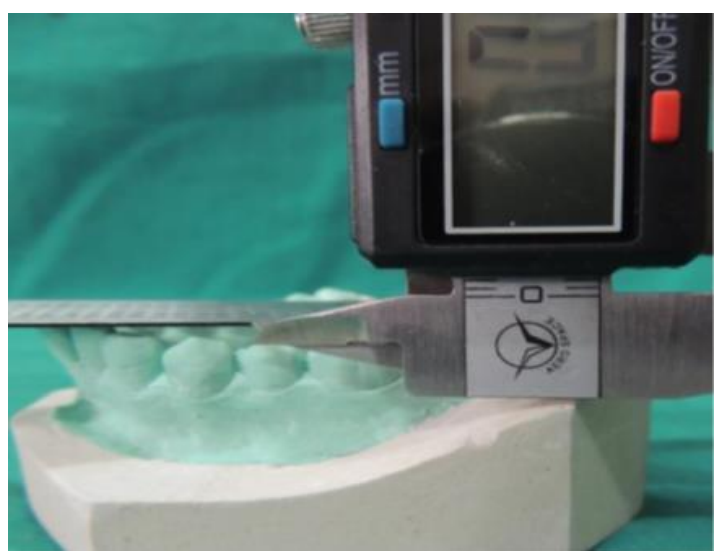

Fig. 2 Measuring the Depth of the curve of Spee (Baldridge Method)

\section{Results}

The mean and standard deviation of the depth of the curve of Spee of the entire sample are shown in Table 1.

Table 1. Differences in depth of curve of Spee in class I, II and III malocclusion among patients in University of North Sumatera Dental Hospital.

\begin{tabular}{|l|c|c|c|}
\hline Malocclusion & N & Mean & SD \\
\hline Class I & 40 & 2.74 & 0.70046 \\
\hline Class II div 1 & 31 & 3.83 & 0.92539 \\
\hline Class II div 2 & 11 & 4.65 & 1.41071 \\
\hline Class II subdiv & 7 & 3.41 & 0.64179 \\
\hline Class III & 11 & 2.34 & 0.95723 \\
\hline Total & 100 & 3.30 & 1.12474 \\
\hline
\end{tabular}

A total of 64 patients had a normal curve of Spee, 23 patients had a deep curve of Spee, and 13 patients had a flat curve of Spee as shown in Table 2. In the class I malocclusion cases, $80 \%$ had a normal curve of Spee, $2.5 \%$ had a deep curve of Spee, and $17.5 \%$ had a flat curve of Spee. In the class II division 1 malocclusion $59.1 \%$ had a normal curve of Spee whereas $40.6 \%$ had a deep curve depth. In the class II division 2 malocclusion, most patients had a deep curve, i.e., $80 \%$ patients had a deep curve, and $20 \%$ had a normal curve of Spee. In the class II subdivision malocclusion, $85.7 \%$ had a normal curve depth, and 14.3\% had a deep curve depth. In class III malocclusion, $54.5 \%$ had a flat curve of Spee, whereas $45.4 \%$ had a normal curve. 
Table 2. Distribution of malocclusion based on depth of curve of Spee among patients in University of North Sumatera Dental Hospital.

\begin{tabular}{|c|c|c|c|}
\hline \multirow{2}{*}{ Group } & \multicolumn{3}{|c|}{ Depth of Curve of Spee } \\
\cline { 2 - 4 } & $<2 \mathrm{~mm}$ (Flat) & $2-4 \mathrm{~mm}$ (Normal) & $>4 \mathrm{~mm}$ (Deep) \\
\cline { 2 - 4 } & $\mathrm{N}$ & $\mathrm{N}$ & $\mathrm{N}$ \\
\hline Class I & 7 & 32 & 13 \\
\hline Class II & 0 & 19 & 8 \\
\hline Div 1 & 0 & 2 & 1 \\
\hline Div 2 & 0 & 6 & 0 \\
\hline Subdiv & 6 & 5 & 23 \\
\hline Class III & 13 & 64 & 13 \\
\hline Total & & & \\
\hline
\end{tabular}

A Pearson correlation coefficient was calculated between all variables as shown in Table 3. A statistically significant positive correlation was present between the depth of the curve of Spee with both overjet and overbite.

Table 3. Correlation between Curve of Spee, overjet and overbite among patients in Univeristy of North Sumatera Dental Hospital.

\begin{tabular}{|l|r|c|}
\hline \multicolumn{1}{|r|}{ Variable } & Overjet & Curve of Spee \\
\hline Overbite & $0.311(0.002)$ & \multirow{2}{*}{$0.500(0.000)$} \\
\hline Curve of Spee & $0.342(0.000)$ & \\
\hline
\end{tabular}

\section{Discussion}

Marshall et al. stated that the curve of Spee depth is minimal in the deciduous dentition; its greatest increase occurs in the early mixed dentition as a result of the eruption of both the permanent first molar and the central incisor [9]. Andrews stated that there is a natural tendency for the curve of Spee to deepen with time because the lower jaw's growth downward and forward sometimes is faster and continues longer than that of the upper jaw. This difference in both the rate and duration of growth causes the lower anterior teeth, which are confined by the upper anterior teeth and lips, to be forced back and up, resulting in crowded lower anterior teeth, deeper overbite and deeper curve of Spee. So, the treatment objective should be to achieve a flat curve as an overtreatment [10].

The curve of Spee increases to a maximum depth with the eruption of the permanent second molars and then remains relatively stable into late adolescence and early adulthood. A possible explanation for the development of the curve of Spee is that permanent mandibular teeth erupt before their maxillary antagonists. This means that, in large measure, the curve of Spee develops as a dental (not skeletal) event [9]. Hence it is important to know the values of the depth of the curve of Spee for the specific age group and in a given population [2].

The findings in Table 1 show that the mean depth of the curve of Spee based on the angle malocclusion group in class I malocclusion was $2.74 \mathrm{~mm}$, in class II division 1 malocclusion was $3.83 \mathrm{~mm}$, in class II division 2 was $4.65 \mathrm{~mm}$, in class II subdivision was $3.41 \mathrm{~mm}$, and in class III malocclusion was $2.34 \mathrm{~mm}$. The findings 
of this research support the results of Nayar et al. who showed that the curve of Spee in class II malocclusion had a significant difference than that of both class I and III malocclusions where the curve of Spee was found deepest in class II malocclusion but flatter in class III malocclusion [4]. The study done by Shannon and Nanda also suggested that Class II malocclusion had a significantly deeper pretreatment curve of Spee measurements than Class I malocclusions and the same case in this study [8]. Furthermore, the curve of Spee is directly proportional to both the overjet and overbite of an individual [5]. A correlation between the curve of Spee and overbite indicated that an increase in overbite coincided with an increase in the depth of the curve of Spee. Ahmed et al. also suggested that the amount of both overbite and overjet significantly influence the variation of the curve of Spee in the mandibular arch. The overjet and overbite in the deep Spee group were significantly larger than in the normal and flat Spee groups [1]. The curve of Spee contributes to set up the anterior overbite and is favorable to the approach of the maxillary and mandibular occlusal planes in mandibular elevation [3].

Overall, the curve of Spee among malocclusion groups was deepest in class II division 2, followed by class II division 1, class II subdivision, class I, and class III. The correlation coefficient of the variables shows that there is a significant correlation between the curve of Spee, overjet, and overbite. Further research is recommended to use subjects from different population to have variations in malocclusion, which are more heterogeneous for data to have a higher degree of validity.

\section{References}

1. Chitra P, Yashpal. The curve of spee- a diagnostic tool. Indian J Appl Res 2014;4 Suppl 11: $147-50$

2. Krishnamurthy S, Hallikerimath RB, Mandroli PS. An assessment of curve of spee in healthy human permanent dentitions: a cross sectional analytical study in a group of young Indian population. J Clin Diagn Res 2017;11 Suppl 1: 53-7.

3. Ahmed M, Erum G, Ahsan T, Nazir R. Influence of malocclusion on the depth of curve of spee. J Pak Med Assoc 2011;61 Suppl 11: 1056-9.

4. Dhiman S. Curve of spee - from orthodontic perspective. Indian J Dent 2015;6 Suppl 4: 199-202.

5. Nayar S, Dinakarsamy V, Santhosh S. Evaluation depth of the curve of spee in class I, class II, and class III malocclusion: a cross sectional study. J Pharm Bioallied Sci 2015;7 Suppl 1: 92-4.

6. Sarraf HA, Aggha NF, Dawoody AD. A comparative study of curve of spee and arch circumference between class I normal occlusion and class II division 1 malocclusion. Al-Rafidain Dent J 2010;10 Suppl 2: 341-6.

7. Graber L, Vanarsdall R, Vig K. Orthodontics: current principles and technique. 5th ed. US: Elsevier Mosby; 2012.

8. Negi SK, Shukla L, Sandhu GPS, Aggarwal M. Investigation of variation in curve of spee, overjet and overbite among class-I and class-II malocclusion subjects and to find sexual dimorphism, if any. J Adv Med Dent Sci Res 2016;4 Suppl 1: 21-26.

9. Marshall SD, Casperse M, Hardinger RR, Franciscus RG, Aquilino SA, Southard TE. Development of the curve of spee. Am J Orthod Dentofac Orthop 2008;134 Suppl 3: 344-51.

10. Batham PR, Tandon P, Sharma VP, Singh A. Curve of spee and its relationship with dentoskeletal morphology. J Ind Orthod Soc 2013;47 Suppl 3: 128-34. 